\title{
Dry granulation of organic powders-dependence of pressure 2D-distribution on different process parameters
}

\author{
Thibaut Lecompte ${ }^{\mathrm{a}, *}$, Pierre Doremus ${ }^{\mathrm{a}}$, Gérard Thomas ${ }^{\mathrm{b}}$, Laurent Perier-Camby ${ }^{\mathrm{b}}$, \\ Jean-Claude Le Thiesse ${ }^{\mathrm{c}}$, Jean-Claude Masteau ${ }^{\mathrm{c}}$, Laurent Debove ${ }^{\mathrm{a}}$

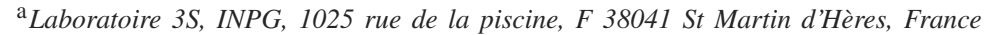 \\ ${ }^{\mathrm{b}}$ Laboratoire Spin, LPMG UMR-CNRS 5148, Ecole Nationale Supérieure des Mines de, St Etienne, 158 Cours Fauriel, F42023 St Etienne, France \\ ${ }^{\mathrm{c}}$ Rhodia, Centre de recherche de Lyon, 55 av. des frères Perret, 69190 St Fons, France
}

\begin{abstract}
Nowadays dry granulation of powders has become a very important research topic because it is the most economic way of granulation, making the particle handling easier, and avoiding the loss of material during particle processing, or particle transfers. This kind of process has been deeply studied but a better knowledge appears necessary to control the great number of parameters of the process. This is particularly important in cases where the nature of the powder may lead to very complex phenomena during compaction.

In order to try and optimise dry granulation process for organic compounds, a roll press has been designed with a series of instruments enabling to control the compaction process. The apparatus consists of three parts: a vertical container with rotating steel blades avoiding arches into which the powder is poured, a feeder transferring the powder towards the rolls; the feeder is equipped with an horizontal helical screw in a cylindrical draft tube $(10 \mathrm{~mm}$ in internal diameter, $500 \mathrm{~mm}$ long) and in the end of the feeder, a junction allows the change from the cylindrical symmetry of the feeder to the prismatic symmetry existing in the roll gap. The roll press $(0-500 \mathrm{kN}$, load per unit length $0-10^{4} \mathrm{kN} \mathrm{m}^{-1}$ ) has been developed to record different major classical parameters: the roll speed, the roll gap, the press strength, the rotation angle, and the feeding rate (between 0 and $20 \mathrm{~g} \mathrm{~s}^{-1}$ ). In comparison with different kinds of roll press described in the literature, in this work an original instrumentation system has been developed to catch specific data. The 3D-pressure distribution profiles at the interface between powder and the roll wall and the drive torque applied to the rolls were measured. A large-sized smooth steel-made roll ( $240 \mathrm{~mm}$ diameter, $50 \mathrm{~mm}$ width) has been chosen to compare the results to the industrial scale.

The results obtained with an organic compound exhibited the dependence-sometimes unexpected—of the rotation angle, the feeding and the rotation speed on the pressure distribution, the roll width, and the drive torque.
\end{abstract}

Keywords: Roll compaction; Powder; Organic materials; Pressure distribution; Driving torque; Screw feeder

\section{Introduction}

The rolling compaction has been used since many decades in several industrial processes. Even though roll compaction has been extensively studied, a lack of knowledge does remain because of a great number of parameters, especially when using organic powders. This study aims at reaching a better understanding of the phenomena occurring during the roll compaction to optimise cohesion and dissolution of

\footnotetext{
* Corresponding author.

E-mail address: lecompte@hmg.inpg.fr (T. Lecompte).
}

the final granules. An instrumented roll press has been developed to record pressure profiles on the powder/rolls wall interface, moment applied on the rolls to drive them and the gap between the rolls.

During powder granulation three steps can be distinguished: (i) feeding of powder to the roll gap, (ii) compaction of powder into dense tapes, (iii) breaking of tapes into granules. The powder can be fed by two ways: by gravity or by force feeding using single or multiple screw feeder (Pietsch, 1991). In our work, a forced feeding has been chosen to obtain a more constant powder flow, as to estimate the influence of each variable on the characteristics 
Table 1

Meaning former compaction experiments

\begin{tabular}{lccc}
\hline Reference & $\begin{array}{l}\text { Roll } \\
\text { diameter } \\
(\mathrm{mm})\end{array}$ & $\begin{array}{l}\text { Roll } \\
\text { width } \\
(\mathrm{mm})\end{array}$ & $\begin{array}{l}\text { Max.wall } \\
\text { speed } \\
\left(\mathrm{mm} \mathrm{s}^{-1}\right)\end{array}$ \\
\hline Simon (2000) & 130 & 50 & 100 \\
Michel (1994) & 100 & 46 & 100 \\
Dec and Komarek (1992) & 304.8 & 50.8 & 48 \\
Jérôme et al. (1991) & 250 & 40 & 353 \\
Shima and Yamada (1984) & 80 & 20.2 & 100 \\
Tundermann and Singer (1969) & 85.2 & 50.8 & 669 \\
Katashinskii and Vinogradov (1965) & 175 & $38-79$ & 28 \\
Lecompte et al. & 240 & 50 & 377
\end{tabular}

of the final tapes. During the compression step, the powder is compacted by passing between two rolls to produce tapes with controlled strength. The third step-breaking tapes-will not be discussed in this paper.

Johanson (1965a,b) and Katashinskii and Shtern (1983a,b) have shown in their theories of rolling compaction that the bigger the roll diameter the more satisfying the cohesion properties of the compacts produced. Serris et al. (2002), studying uniaxial compression of several organic powders, have observed that the longer the underpressure and up-to-pressure duration, the more dense and cohesive the compacts. Johanson (1965a,b) introduced the nip angle, where the powder starts to be driven by the roll walls. This nip angle value is less than $10^{\circ}$ and does not depend on the roll diameter. Then increasing the roll diameter brings about an enlargement of the compaction area and increases the time during which powder grains are submitted to the pressure. As a consequence the tapes will acquire a better cohesion. Table 1 shows the list of different roll diameters used during earlier experiments. In most cases, quite small diameters are chosen. These diameters correspond to roll granulators available in the market. The originality of the present study lies in the fact that the instrumented roll press has totally been developed in our laboratory, with the objective of simulating industrial conditions: rolls with quite a big diameter and large enough to avoid edge effects, under a huge maximum force. Such an experimental assembly extends the scope of the study with results allowing more reliable extrapolation to larger industrial units.

Torque measurements during compaction have been neglected in earlier experiments. However, the torque monitoring appears really interesting to reach a better understanding of this process and would be helpful for modelling. Therefore a torque sensor has been set on a driving axle of our roll press.

Simon and Guigon (2003) (Guigon and Simon, 2003) have observed that the density was varying along the tapes produced. This has been connected to the geometry of the feeding screw and rotational motion introducing heterogeneous feeding. To investigate on this observation, our roll has been equipped with three pressure sensors, located at differ- ent points around the diameter and along the roll's width, to measure the radial and axial pressure distribution.

This original set of equipment has been assembled and used to study the behaviour of an organic powder, and find out the best conditions to produce satisfactory tapes in the best way.

\section{Press technology}

A roll press has been designed with a series of instruments enabling to control the compaction process. Fig. 1 shows a roll press set up with two main parts: the feeding unit and the roll press assembly.

\subsection{Container, feeding box and screw (Fig. 1, Mark 1)}

First, the powder is poured into a vertical container with rotating steel blades avoiding arches. Then with a screw feeder the powder is fed between the rolls. Simon and Guigon (2003) (Guigon and Simon, 2003) have observed that feeding obtained by only one endless screw were neither perfectly stable nor homogeneous and had some effects on the tape density distribution. In this work, a single horizontal screw-closer to industrial conditions-has been used. At the end of the feeder, a junction allows the change from the cylindrical symmetry of the feeder to the prismatic symmetry existing in the roll gap. The motor coupled with the screw was chosen to reach feeding flow rates just over $22 \mathrm{~g} \mathrm{~s}^{-1}$.

\subsection{Press and rolls}

The roll press (Fig. 1, Mark 2) can be used either in speed controlled mode or in force controlled mode. According to the previous comments, the rolls (Fig. 1, Mark 3) - $240 \mathrm{~mm}$ diameter - are very large for a lab testing. The choice of the

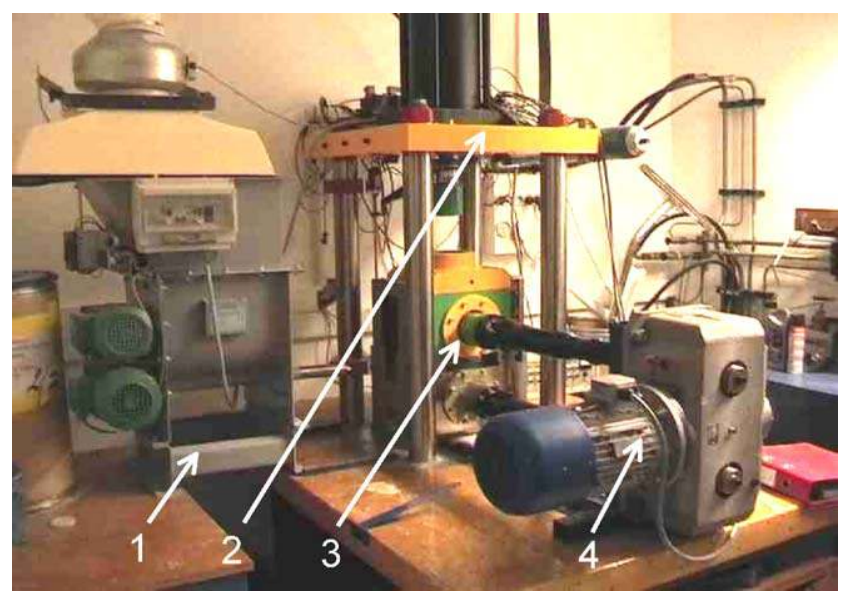

Fig. 1. Overview of the roll press set up: (1) feeding system; (2) hydraulic press; (3) rollers; (4) actuator. 
roll width, $50 \mathrm{~mm}$, was a compromise between avoiding the edge effects around the rolls and limiting the driving torque. The force by unit length applied on the roll's wall could vary from 0 to $10^{7} \mathrm{~N} \mathrm{~m}^{-1}$. The walls of the rolls are smooth as to simplify later numerical simulations.

The proper running conditions for the compaction are mainly insured by the exact synchronisation of both rolls. One single motor is used, coupled with a step-down made up of an endless screw and two identical toothed wheels. This actuator (Fig. 1, Mark 4) reaches an angular speed up to $3.14 \mathrm{rad} \mathrm{s}^{-1}$ (wall speed up to $377 \mathrm{~mm} \mathrm{~s}^{-1}$ ), with a moment from 0 to $1000 \mathrm{Nm}$ on each axle.

\section{Instrumentation}

The interesting parameters to be followed during the compaction are the torque applied by each roll on the powder bed, the roll gap and obviously the pressure at the powder/wall interface. To measure each of them, classical as well as original sensors have been installed.

\subsection{Classical sensors}

Table 2 lists the position of the 'classical' sensors used in the assembly.

\subsection{Powder/roll interface pressure measurement}

Three pressure sensors have been used. They have been placed at $120^{\circ}$ position from each other as shown in Fig. 2. One is located in the roll symmetry plane, the second at one-thirds and the third at two-thirds of the roll half-width (Fig. 2). On the roll wall, a $2 \mathrm{~mm}$ diameter pin is placed in contact with the powder. At the other end, it transmits an effort on a little steel plate that is then subjected to a threepoints bending. A strain gauge is bonded under this plate. Connexions pass through the roll shaft and are connected to a Wheaston bridge using a turning commutator. Fig. 3 shows this pressure sensor assembly.
These sensors were calibrated on a laboratory press. The pressure sensors, the instrumented roll and its axle have been assembled and placed on a V-support. Then the force was directly applied on the pin with a punch. The theoretical values of calibration are deduced from the gain $(K)$ and

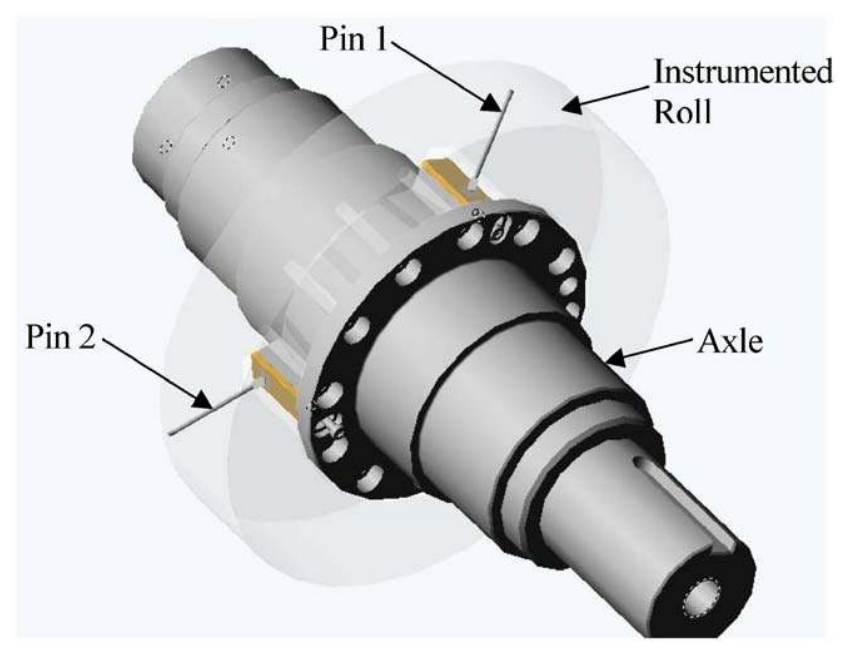

Fig. 2. Location of measurement pins: view of the instrumented roll (in transparency) with the pins screwed on its axle: two of the three pins are visible: they are located at $120^{\circ}$ each from other, pin 1 measures the centre pressure and pin 2 the edge pressure.

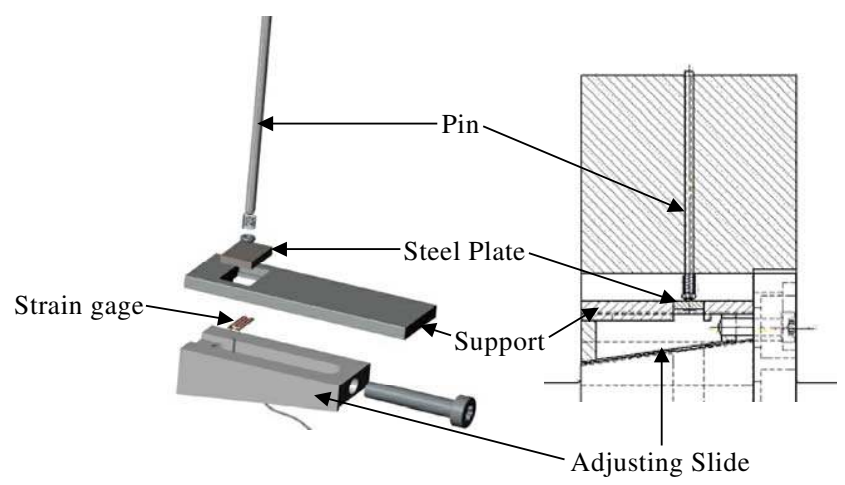

Fig. 3. Pressure measurement assembly in the powder/rolls area.

Table 2

'Classical' sensors

\begin{tabular}{|c|c|c|c|c|c|c|}
\hline Measurement & Kind of sensor & Supplier & model no. & Technology & Range & Sensitivity \\
\hline $\begin{array}{l}\text { Torque applied on each } \\
\text { motor-reducer axle }\end{array}$ & Torque sensor & Algosys ${ }^{\circledR}$ & DR12 & Strain gauges & $0 \rightarrow 1000 \mathrm{Nm}$ & $<1 \mathrm{Nm}$ \\
\hline $\begin{array}{l}\text { Gap \& parallelism } \\
\text { between rolls }\end{array}$ & $\begin{array}{l}\text { Moving } \\
\text { sensors }\end{array}$ & Solartron ${ }^{\circledR}$ & $922-503$ & LVDT & $-1 \rightarrow 4 \mathrm{~mm}$ & $1 \mu \mathrm{m}$ \\
\hline Press on roll effort & Effort sensor & $\begin{array}{l}\text { Bourdon } \\
\text { Sedeme }{ }^{\circledR}\end{array}$ & $67-528$ & Strain gauges & $0 \rightarrow 5 \times 10^{5} \mathrm{~N}$ & $1000 \mathrm{~N}$ \\
\hline Press displacements & Moving sensor & $\operatorname{MTS} \circledast$ & 0132-0229 & Magnetostriction & $0 \rightarrow 500 \mathrm{~mm}$ & $0.01 \mathrm{~mm}$ \\
\hline $\begin{array}{l}\text { Angular position of the } \\
\text { three pressure sensors }\end{array}$ & Angular sensor & $\begin{array}{l}\text { Vishay }{ }^{\circledR} \\
\text { Spectrol }\end{array}$ & $1045-0000$ & Potentiometer & $0 \rightarrow 360^{\circ}$ & $0.1^{\circ}$ \\
\hline
\end{tabular}


the input tension $\left(U_{\mathrm{exc}}\right)$ of the Wheatstone bridge, the gauge factor $(k)$, and the plate's characteristics (thickness $s$, length $L$, width $W$ and Young modulus $E$ ). Given an input force $F$, the output voltage $U$ can be obtained as

$U=\frac{3 k K L U_{\mathrm{exc}}}{2 E W s^{2}} F$.

The theoretical coefficient of proportionality between the applied effort and the measured voltage should be $2.09 \times$ $10^{-2} \mathrm{~V} / \mathrm{N}$. The experimental values are, respectively, $1.8 \times$ $10^{-2}, 1.9 \times 10^{-2}$ and $1.97 \times 10^{-2} \mathrm{~V} / \mathrm{N}$ for the three sensors. These values do not vary with the force rate and no hysteresis phenomenon was observed. Errors of gauge's position when sticking and of plate cutting are the principal reasons for the difference observed between theoretical and measured coefficients.

\section{Results}

The initial experiments were carried out on an organic powder placed in an instrumented die. This powder has already been studied in uniaxial compaction experiments (Serris, 2002). Fig. 4 shows the evolution of the relative density versus the mean axial pressure in the powder bed during uniaxial compaction. No viscous behaviour was observed for speeds of compaction varying between 0.01 and $10 \mathrm{~cm} \mathrm{~s}^{-1}$. The friction coefficient between the wall of the die and the powder was also calculated from these experiments (Fig. 5), by using a slab method (Doremus et al., 2000). Below a relative density of 0.85 , the pressure remains very low, and the results appear too noisy and lack the accuracy to be valid. Some experiments carried out at low densities with an annular cell have been showing an internal angle between $38^{\circ}$ and $43^{\circ}$ and a wall-powder friction coefficient about 0.15 . So this coefficient is constant, equal to 0.15 until a relative density of 0.85 and decreases until 0.045 at high densities. It is probably due to the smoothing of the powder grains on the die wall. The Young modulus $(E=34300 \mathrm{MPa})$ of the compact was measured from a simple compression test. These data are useful for modelling, to compare the roll compaction behaviour of different powders and to understand the phenomena observed during compaction. This work deals with the process parameters and particularly their interdependence. Then all the experiments were carried with this single organic powder.

\subsection{Feeding and rolling}

The gap, moment and pressures were measured for feeding rates varying between 0 and $6 \mathrm{~g} \mathrm{~s}^{-1}$, for three different angular rolling speeds $0.26,0.54$ and $1.07 \mathrm{rad} \mathrm{s}^{-1}$, corresponding to a roll speed of $31.5,64$ and $128 \mathrm{~mm} \mathrm{~s}^{-1}$, respectively, and for a force per unit length from 210 to $2010 \mathrm{kN} \mathrm{m}^{-1}$.

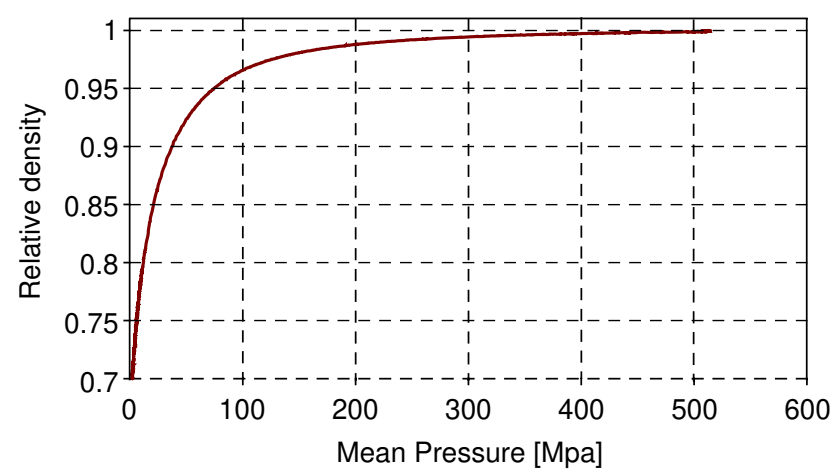

Fig. 4. Variations of the relative density versus the mean axial pressure-compaction in instrumented die.

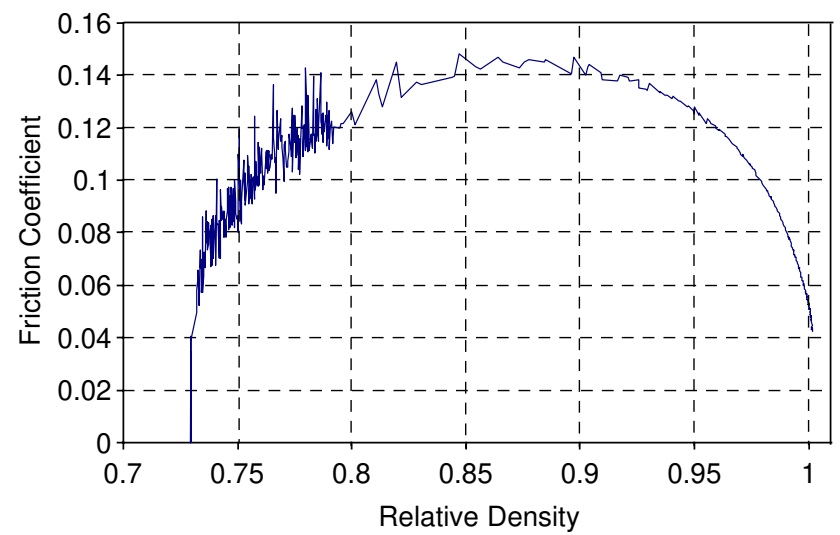

Fig. 5. Variations of the wall/powder friction during a compaction in instrumented die.

During the experiments, a correlation was observed between the rolling speed and the feeding rate. Indeed, when the feeding rate and angular speed vary keeping a constant feeding rate to rolling speed ratio, output values are not subject to variations. Goidin-Jérôme et al. (1992) have introduced the working coefficient, as the roll speed-screw speed ratio. They assume that this coefficient controls the functioning conditions of the process. In another paper (Hervieu et al., 1994), the authors assume that on pharmaceutical powders, the speed adjustments are more important than the usual pressure adjustments, because the feeding screw has an important part in pre-compaction. This process parameter can be considered as the pertinent interesting input variable instead of both feeding flow rate and roll angular speed. In this work, the feeding rate-rolling speed ratio expressed in $\mathrm{g} \mathrm{m}^{-1}$ will be named "feeding-rolling ratio". This has been preferred to the working coefficient to enable the transposition between two presses (different in roll diameter and in feeding characteristics).

To create a pre-compaction pressure in the feeding area, the endless screw had to supply on the powder, whereas the rolls tend to stop its movement. So when the screw turned too slowly compared with rolls, there was a lack of 


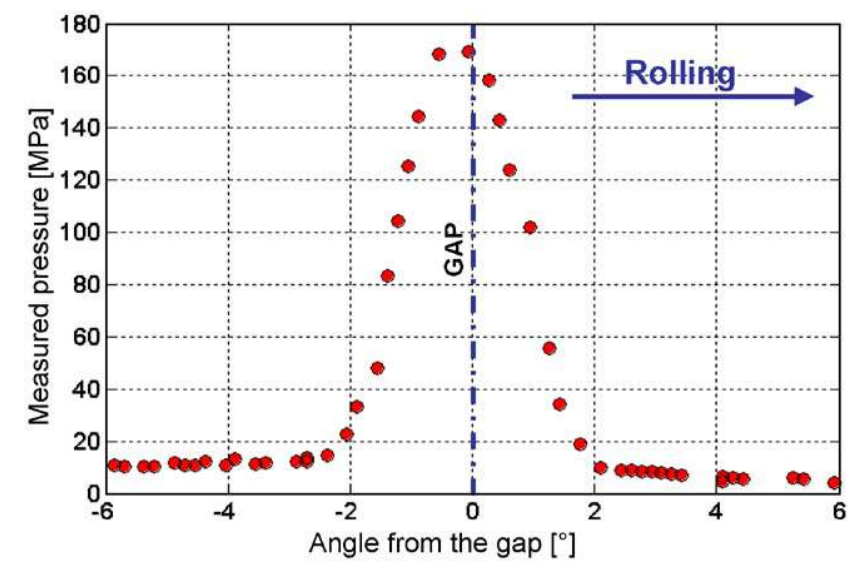

Fig. 6. Typical pressure profile obtained by the sensors: profile is asymmetrical and not centred at the roll gap.

powder: the system was subfed and measurements did not appear satisfying. In addition, the compacts obtained were of poor quality. Conversely, when the feeding rate was too fast, over-feeding occurred leading to machine's blocking (screw motor, roll actuator or all together).

\subsection{Radial pressure on roll}

Fig. 6 shows the results obtained from the pressure sensors. Angle zero corresponds to the angular location of the roll gap. As written by Chekmarev et al. (1963), profiles are asymmetrical and not always centred on the roll gap. The maximum pressure occurs for angles going from 0 to $3^{\circ}$ before the roll gap. In addition, the higher the effort or the feeding-rolling ratio, peak pressure was further from the roll gap. To validate the reliability of the sensors, a data processor was set up. According to a supposed steady state, the three series of points obtained during the same roll rotation were put back in the same line. The curves drawn in this way for several consecutive rotations are practically similar with a small error $(3 \%)$. This observation not only validates the hypothesis of continuous rate but also seems to be in contradiction with Simon and Guigon (2003) (Guigon and Simon, 2003), who have found that the screw rotation was creating heterogeneity in the density distribution (and then in pressure distribution). This will be discussed hereafter.

So screw effects could be neglected and a planar symmetry can be considered in the process. Then the symmetrical curves have been drawn, and the five curves have been fitted by curves of Johanson's type (Johanson, 1965a). The software used was Matlab ${ }^{\circledR}$. This software enables the minimisation of the difference between a model curve and experimental data by the least-squares method. The $2 \mathrm{D}$ curves were extrapolated to 3D from spline consisting of polynomial curves. The surfaces obtained in this way reflect the pressure distribution along the width and compaction area in the wall. The volume under this surface was calculated and compared with the force applied by the press. The calculations gave the same values, with a small error (about 5\%): our sensors seems to be quite reliable. Figs. 7 and 8 show top views of surfaces obtained with variations of feeding-rolling ratio and effort. The higher the feeding-rolling ratio or the pressing, the more homogeneous and the more asymmetrical the pressure distribution.
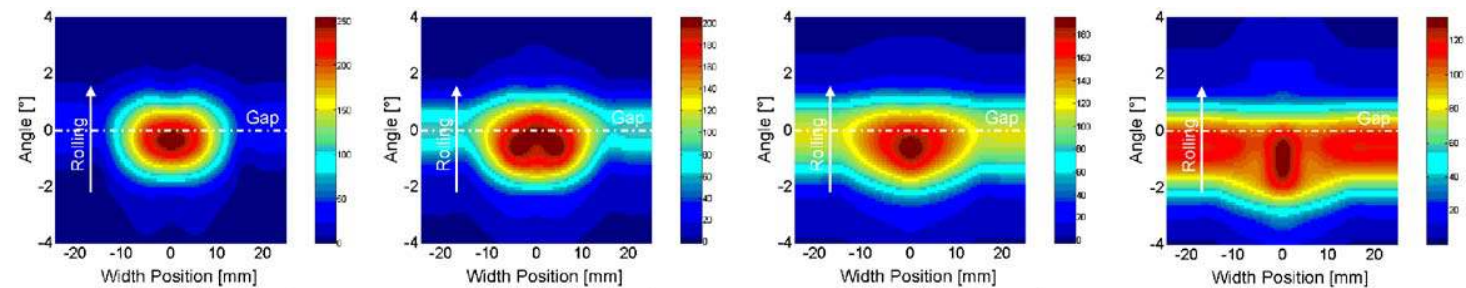

Fig. 7. Top views of pressure distribution (MPa) for different pressing forces with a feeding-rolling ratio $R=62 \mathrm{~g} \mathrm{~m}^{-1}$ : with an increase in pressing, the pressure distribution gets more homogenous and the maximum pressure goes further from the roll gap.
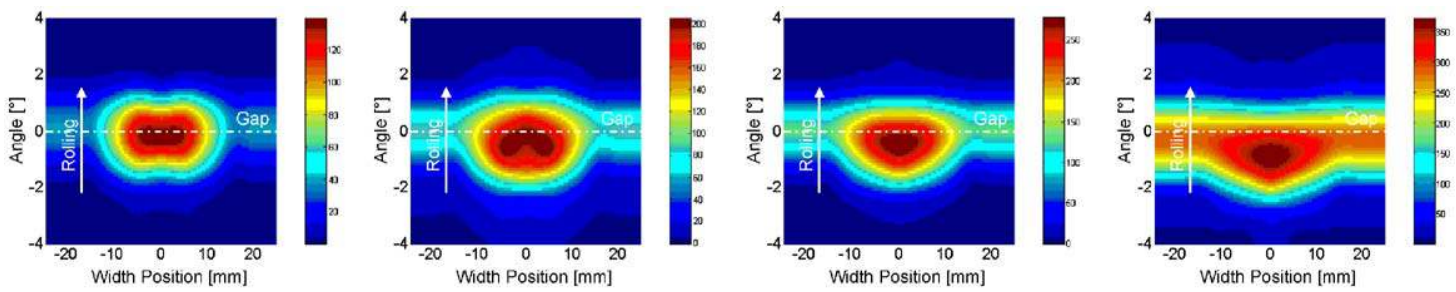

Fig. 8. Top views of pressure distribution (MPa) for different feeding-rolling ratios with a force per unit length $F_{1}=810 \mathrm{kN} \mathrm{m}^{-1}$ : with an increase of feeding/rolling ratio, the pressure distribution get more homogenous and the maximum pressure goes further from the roll gap. 


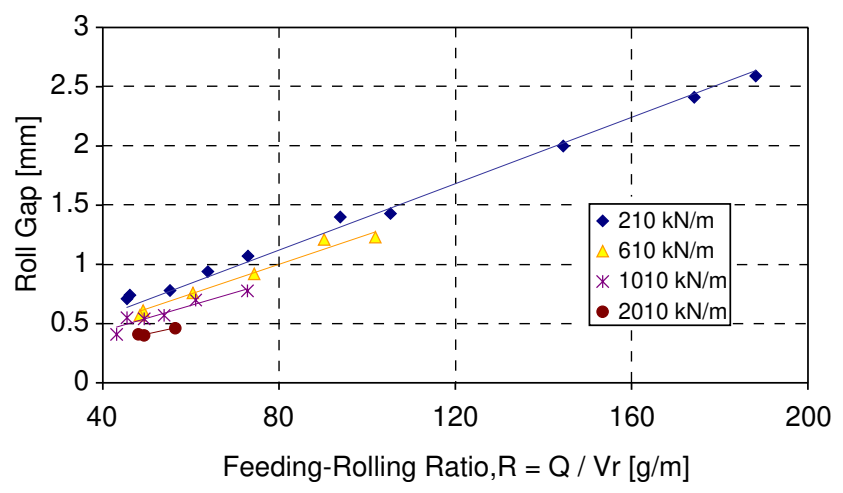

Fig. 9. Roll gap as a function of the feeding-rolling ratio, for different values of pressing effort.

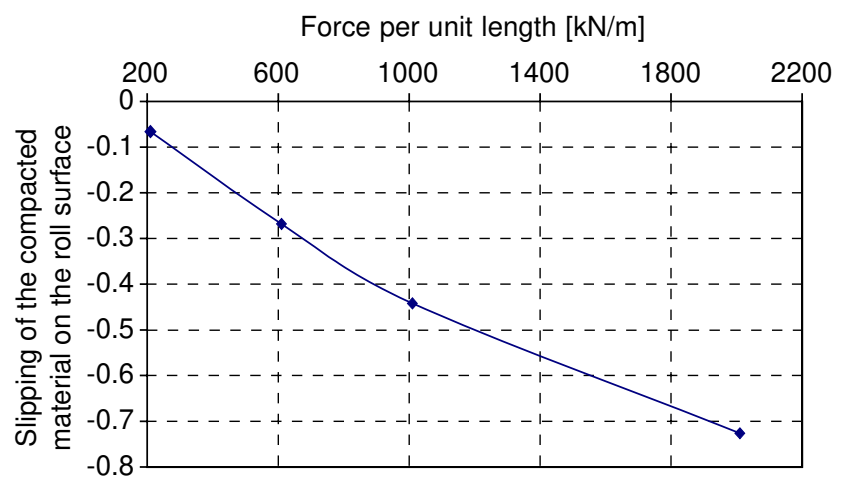

Fig. 10. Slipping of the compacted tape on the roll surface as a function of the pressing force: a negative slipping is found: at the roll gap, the compacted tapes go faster than the roll wall.

\subsection{Roll gap and driving torque}

It sometimes had to wait for dozens of rotations before settling a true stationary steady state. Fig. 9 shows the roll gap as a function of the feeding-rolling ratio for different loads. The gap looks to be increasing linearly with this ratio. Using a relation found by Simon (2000), an expression of the gap $h_{0}$ as a function of the roll width $L$, the feeding-rolling ratio $R$, the density of the compacted material $\rho_{s}$ and the slipping of the compacted material on the roll surface $\zeta$ was used

$h_{0}=\frac{R}{L \rho_{s}(1-\zeta)}$.

The slipping can be deduced from Eq. (2) and the curve slopes of Fig. 9. Results are shown in Fig. 10. The compacts at the roll gap go faster than the walls, and the higher the effort, the faster the slip. This observation compliments some earlier experimental works (Shima and Yamada, 1984; Schönert and Lubjhun, 1993) and significantly the theory of Katashinskii and Shtern (1983a,b).

Fig. 11 shows the evolution of the moment applied on rolls by each driving axle, for different loads. Without any

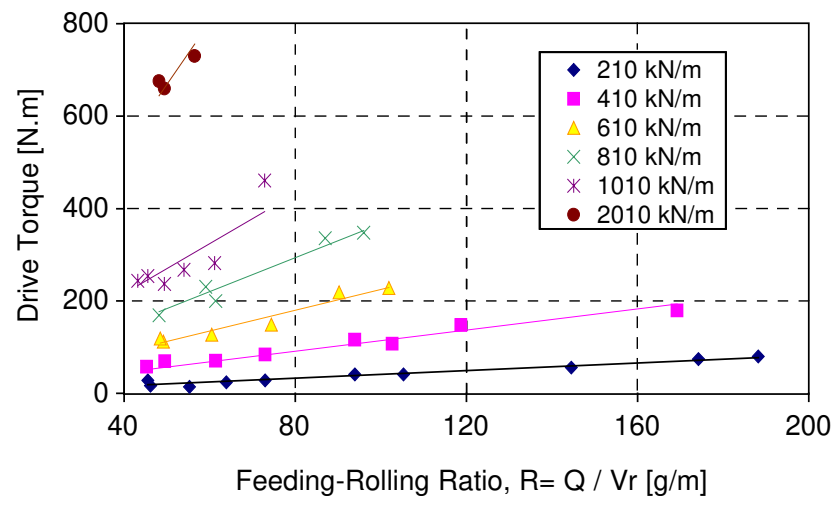

Fig. 11. Driving torque as a function of the feeding-rolling ratio, for different values of pressing effort.

load, a moment of about $35 \mathrm{Nm}$ appeared. It has been subtracted from the measurements to obtain valuable data for the driving torque value. This torque seems to increase linearly with the feeding-rolling ratio and the slopes of the straight lines increase with the effort. Katashinskii and Shtern based their theory on the existence of a neutral angle, before which the powder goes slower than the roll walls and after which it goes faster. According to the results found for the gap, we can accept this hypothesis. Let us consider that when powder bed has reached its maximum density, it can escape in three directions: towards right roll side, left roll side and ahead. Ahead, the powder release can be assumed by a longitudinal relaxation, even if the powder bed has not yet crossed the gap. So a displacement of the powder in the direction of the wall during rolling seems possible. Then the powder bed would tend to slow down the rolling before the neutral angle and train it after. This phenomenon could explain why the maximum pressure position moves back when feeding-rolling ratio or pressing increase. It could also explain why the driving torque increases with feeding-rolling ratio: the more compacted the powder bed, the more asymmetrical the profiles, and the higher the "stopping-training" effect.

\section{Discussion}

The results concerning the pressure during compaction by rolling were found to differ from those described by Simon and Guigon (2003) (Guigon and Simon, 2003): they have observed variations due to the screw feeder rotation, while here the pressure was constant and symmetrical. It could be explained as follows: in this work the screw's end was located further from the rolls than during Simon's experiments. Lammens and Pörtner (2000) observed by transparency that the density of tapes obtained from roll press with a screw feeder was more uniform with an higher (controlled) roll gap. So when the volume of powder bed in the roll gap is bigger, rearrangements are possible in this zone, making the density more uniform. In the present case a buffer area is 
probably appearing and significantly reducing screw's turning effects. Nevertheless, these effects were observed when the machine was underfed: no pre-compaction area occurred and the screw lay small piles at random.

The dimensions and circular section of the endless screw must be compared to the dimensions and the rectangular section of the space between rolls. A great part of the powder was piled near the median plane of the rolls. Then whenever the press effort remains small enough and the feeding rate slow compared with roll speed, the powder presents a tendency to stay in the centre.

On the contrary, homogeneous pressure along the roll width is evidenced for high feeding-rolling ratio and/or high-pressing values. When the force increases, a roll gap decrease is observed. When efforts become higher while the feeding-rolling ratio is kept constant, the powder crosses the gap in a more compact state. But the powder bed cannot exceed a certain density, and the powder grains spread all over the roll width towards the edges. In addition, the friction coefficient decreases with pressure. Then an increase of the pre-compaction pressure enables the powder to slip more easily on rolls. As rigid plates have been applied to the roll sides the powder is finally more regularly distributed from the centre to the edges. Then an increase of pressure logically increases homogeneity of the load between the rolls, and probably also the homogeneity of the density and mechanical properties of the tape. With an increase of the feeding-rolling ratio, a similar phenomenon occurs: too much powder tend to be in the centre area and is then redirected towards the side areas. This is in contradiction with Hervieu et al. (1994). The authors assume that the working coefficient is preponderant and that the effects of variations of pressure variations are negligible. This work shows that an increase of compaction force or feeding-rolling ratio has the same consequence: it makes the pressure distribution uniform and then increases the quality of tapes.

So optimisation of this process would appear simpler: applying the maximal force, with the highest flow rate and the slowest rolling speed. But the yield stress of the compacted tape limits the force. Moreover, Sheskey and Hendren (1999) found that high pressures on polymer materials with low feeding rates favour fine powder production and induce tape collapses, whereas variations of roll and screw speeds present little influence on the strength of the produced tapes.

On the contrary, a critical rolling speed, due to the air flow into the powder bed, was firstly observed by Spinov and Vinogradov (1967) with a feeding by gravity and confirmed by Pietsch (1991). With a desaeration system and a feeding screw, this phenomenon is reduced. However, when rolling speed and feeding rate are high, the air cannot leave the powder bed and is more confined and compressed into the produced tape. Keeping the same feeding-rolling ratio, and so the same pressure profiles on rolls, an increase of the rotation speed augments the final porosity of tapes from the air release, and reduces their strength. So the tape quality limits the inner process parameters.
In addition, the higher the press force, the faster the increase of driving torque developed with the feeding-rolling ratio.

Taking into account industrial and economical considerations, and supposing the powder properties to be fair enough for such a process, the choice of input values could be fixed by three criteria: (i) the flow rate realised by the screw, corresponding to the production rate (neglecting the leak of fine powders); (ii) the cohesion and the density distribution realised by the press on powder; (iii) the energy lost by driving the rolls.

\section{Conclusion}

The instrumented roll press developed allows measuring and determining radial pressure profiles in the densification area, the roll gap and driving torque. The pressure profiles observed in this work look in two dimensions like those obtained in earlier articles (the first to observe such profiles were Chekmarev et al., 1963): the nip angle is about a few degrees and the maximum of pressure is not always applied exactly in the gap centre, but up to $3^{\circ}$ before. These facts, together with torque curves confirm the validity of the hypothesis of a neutral angle before which the powder goes slower than rolls and after which it goes faster (Katashinskii and Shtern, 1983a).

This press has been developed for working in close-toindustrial conditions, to make extrapolations towards production processes easier. It extends the experimental field and gives a more accurate idea about the influence of the process parameters on nip angle, maximum of pressure, neutral angle, pressure profiles and distribution, cohesion and homogeneity of produced compacts.

The experimental results obtained from this new roll press set up has given a better understanding of the link between the different inner process parameters, intrinsic characteristics of powder and those of produced tapes. It would also give significant data to formulate realistic numerical simulation of the rolling powder compaction.

\section{Acknowledgements}

The authors would like to acknowledge support for this work from Rhodia Lyon Research Centre, and the French Region Rhône-Alpes through its material engineering program.

\section{References}

Chekmarev, A.P., Klimenko, P.A., Vinogradov, G.A., 1963. Investigation on specific pressure, specific friction, and the coefficient of friction during metal powder rolling. Soviet Powder Metallurgy Metal and Ceramics 112-115.

Dec, R.T., Komarek, R.K., 1992. Experimental investigations of roller press compaction. Powder Handling and Processing 4, 35-38. 
Doremus, P., Toussaint, F., Alvain, O., 2000. Simple tests standard procedure for the characterisation of green compacted powder. In: Zavaliangos, A., Laptev, A (Eds.), Proceedings of the NATO Advanced Research Workshop on Recent Developments in Computer Modeling of Powder Metallurgy Processes. IOS Press, Amsterdam, pp. 29-41.

Goidin-Jérôme, E., Delacourte, A., Guyot, J.C., Dehont, F., Hervieu, P., 1992. Modifications des propriétés d'une poudre á l'aide d'un compacteur granulateur. STP Pharma sciences 2 (4), 320-324.

Guigon, P., Simon, O., 2003. Roll press design-influence of force feed systems on compaction. Powder Technology 4609, 1-8.

Hervieu, P., Dehont, F., Jérôme, E., Delacourte, A., Guyot, J.C., 1994. Granulation of pharmaceutical powders by compaction, an experimental study. Drug Development and industrial pharmacy 20 (1), 65-74.

Jérôme, E., Delacourte, A., Leterme, P., Guyot, J.C., 1991. The measurement of resulting force on a roll compactor. Drug Development and industrial pharmacy 17 (12), 1571-1591.

Johanson, J.R., 1965a. A rolling theory for granular solids. ASME 30, 842-848.

Johanson, J.R., 1965b. Factors influencing the design of roll-type briquetting presses. Ninth Biennale Conference of the international briquetting association, 17-31.

Katashinskii, V.P., Shtern, M.B., 1983a. Stress-strain state of powder being rolled in the densification zone. Part 1. Soviet Powder Metallurgy and Metal Ceramics 22 (11), 882-885.

Katashinskii, V.P., Shtern, M.B., 1983b. Stress-strain state of powder being rolled in the densification zone. Part 2. Soviet Powder Metallurgy and Metal Ceramics 22 (12), 972-976.

Katashinskii, V.P., Vinogradov, G.A., 1965. The rolling of a metal powder in a mill with a single driving roll. Soviet Powder Metallurgy and Metal Ceramics 2, 435-437.

Lammens, R.F., Pörtner, C., 2000. Control of product quality during dry granulation. Proceedings of third World Meeting APV/APGI, Berlin, Avril, pp. 69-70.
Michel, B., 1994. Contribution à l'étude de l'agglomération des poudres en presse à rouleaux lisses. Université de technologie de Compiègne, Ph.D. Thesis.

Pietsch, W., 1991. Size Enlargement by Agglomeration. Wiley, New York. Schönert, K., Lubjhun, U., 1993. Angle of compression and throughput in high pressure grinding rolls. Zement-Kalk-Gips 2, 34-39.

Serris, E., 2002. Influence des conditions de compression sur les propriétés physico-chimiques des comprimés issus de poudres organiques. Ph.D. Thesis, Ecole nationale supérieure des Mines de St Etienne.

Serris, E., Perier-Camby, L., Thomas G., 2002. Evolution and modeling porosity changes versus pressure or time: a quasi chemical approach of powder compaction. Proceedings of the Fourth World Meeting on Pharmaceutics, Biopharmaceutics and Pharmaceutical Technology. Florence, 8-11 April, p. 61.

Sheskey, P.J., Hendren, J., 1999. The effects of roll compaction equipment variables, granulation technique, and HPMC polymer level on a controlled-release matrix model drug formulation. Pharmaceutical Technology 20 (1), 90-104.

Shima, S., Yamada, M., 1984. Compaction of metal powder by rolling. Powder Metallurgy 27 (1), 39-44.

Simon, O., 2000. Etude expérimentale de l'interaction Alimentationcompaction dans une presse à rouleaux lisses alimentée par une vis horizontale. Ph.D. Thesis, Université de technologie de Compiégne.

Simon, O., Guigon, P., 2003. Correlation between Powder packing properties and roll press compact heterogeneity. Powder Technology 4641, 1-8.

Spinov, V.A., Vinogradov, G.A., 1967. Experimental investigation of specific forces in powder rolling. Soviet Powder Metallurgy and Metal Ceramics 673-675.

Tundermann, J.H., Singer, R.E., 1969. The flow of iron powder during roll compaction. Powder Metallurgy 12 (23), 219-242. 